\title{
THE STEFFENSEN-POPOVICIU MEASURES IN THE CONTEXT OF QUASICONVEX FUNCTIONS
}

\section{Constantin P. Niculescu And Marius M. Stănescu}

Abstract. We discuss the extension of Jensen's inequality to the framework of quasiconvex functions and of signed measures.

Mathematics subject classification (2010): 26A51, 26B25, 26D15, 28A10.

Keywords and phrases: Jensen's inequality, convex function, quasiconvex function, signed measure, Rayleigh measure, Cauchy's interlace theorem.

\section{REFERENCES}

[1] A. Cambini and L. M. Martein, Generalized Convexity and Optimization. Theory and Applications, Lecture Notes in Economics and Mathematical Systems 616, Springer-Verlag, Berlin Heidelberg, 2009.

[2] A. M. FinK, A best possible Hadamard Inequality, Math. Inequal. Appl. 1 (1998), 223-230.

[3] A. Florea AND C. P. Niculescu, A Hermite-Hadamard inequality for convex-concave symmetric functions, Bull. Math. Soc. Sci. Math. Roumanie 50, 2 (2007), 149-156.

[4] P. C. Hammer, The midpoint method of numerical integration, Math. Mag. 31 (1958), 193-195.

[5] E. Hewitt And K. M. Stromberg, Real and Abstract Analysis, Springer-Verlag, Second printing corrected, Berlin Heidelberg New York, 1969.

[6] R. A. Horn And Ch. R. E. Johnson, Matrix analysis, Cambridge University Press, Cambridge, 2013.

[7] J. L. W. V. JENSEN, Sur les fonctions convexes et les inégalités entre les valeurs moyennes, Acta Math. 30 (1906), 175-193.

[8] S. Johansen, A Representation Theorem for a Convex Cone of Quasi Convex Functions, Math. Scandinavica 30 (1972), 297-312.

[9] S. Kerov, Interlacing measures, Preprint LaBRI 1116-96 (1996) 1-53, Université de Bordeaux-I, published in Kirillov's seminar on representation theory, Amer. Math. Soc. Transl. Ser. 2, 181, Amer. Math. Soc., RI, 35-83 (1998), Providence, 1998.

[10] S. M. MALAMUD, Inverse spectral problem for normal matrices and the Gauss-Lucas theorem, Trans. Amer. Math. Soc. 357 (2005), 4043-4064.

[11] M. V. Minai And C. P. Niculescu, A simple proof of the Jensen type inequality of Fink and Jodeit, Mediterr. J. Math. 13, 1 (2016), 119-126.

[12] K. S. Miller AND S. G. SamKo, Completely monotonic functions, Integr. Transf. and Spec. Funct. 12, 4 (2001), 389-402.

[13] C. P. Niculescu, Choquet theory for signed measures, Math. Inequal. Appl. 5 (2002), 479-489.

[14] C. P. NiculesCu, The Hermite-Hadamard inequality for functions of a vector variable, Math. Inequal. Appl. 5 (2002), 619-623.

[15] C. P. Niculescu, On a result of G. Bennett, Bull. Math. Soc. Sci. Math. Roumanie 54 (2011), 261267.

[16] C. P. Niculescu And L. E. Persson, Convex Functions. Basic Theory and Applications, Universitaria Press, Craiova, 2003.

[17] C. P. Niculescu And L. E. Persson, Old and new on the Hermite-Hadamard inequality, Real Analysis Exchange 29, 2 (2003/2004), 663-686. 
[18] C. P. Niculescu And L. E. Persson, Convex Functions and their Applications. A Contemporary Approach, CMS Books in Mathematics Vol. 23, Springer-Verlag, Berlin-Heidelberg-New York, 2006.

[19] C. P. Niculescu AND I. RovenţA, Relative Convexity and Its Applications, Aequationes Math. 89, 5 (2015), 1389-1400.

[20] C. P. Niculescu And C. Spiridon, New Jensen-type inequalities, J. Math. Anal. Appl. 401, 1 (2013), 343-348.

[21] J. PeČarić, F. Proschan and Y. L. Tong, Convex functions, partial orderings, and statistical applications, Academic Press, Boston, 1982.

[22] R. R. PhelPS, Lectures on Choquet's Theorem, 2nd ed., Springer-Verlag, Berlin-Heidelberg-New York, 2001.

[23] T. Popoviciu, Notes sur les fonctions convexes d'ordre superieur (IX), Bull. Math. Soc. Roum. Sci. 43 (1941), 85-141.

[24] D. Romik, Explicit formulas for hook walks on continual Young diagrams, Adv. Appl. Math. 32 (2004), 625-654.

[25] B. Simon, Convexity. An Analytic Viewpoint, Cambridge University Press, Cambridge, 2011.

[26] J. ŠREMR, Absolutely continuous functions of two variables in the sense of Carathéodory, Electronic Journal of Differential Equations (EJDE-2010) 154 (2010), 1-11.

[27] J. F. STEFFENSEN, On certain inequalities and methods of approximation, J. Inst. Actuaries 51 (1919), 274-297.

[28] E. Talvila And M. W. Wiersma, Simple derivation of basic quadrature formulas, Atlantic Electronic Journal of Mathematics 5, 1 (2012), 47-59. 